\title{
Jovens produtores culturais de favela
}

\author{
Maria Livia de Tommasi \\ Universidade Federal Fluminense (UFF)
}

Neste artigo, analiso o material coletado no âmbito de uma pesquisa de caráter etnográfico que desenvolvo desde 2010 no Rio de Janeiro, no contexto da qual realizei algumas entrevistas temáticas com jovens produtores culturais moradores de favelas. Ouvindo seus depoimentos, observando suas práticas, procuro compreender as especificidades dessas atividades, as qualidades requeridas para exercê-las e os entraves encontrados. Situo minhas indagações no contexto da centralidade assumida pelo campo da cultura como um recurso, no âmbito das intervenções de requalificação urbana e das transformações ocorridas no mundo do trabalho. As favelas, historicamente consideradas territórios da pobreza e da violência, hoje são celebradas como territórios das oportunidades.

Palavras-chave: Juventude. Empreendedorismo. Favela. Arte e cultura. 


\section{Favela's young cultural producers}

In this paper, I analyze the material collected as part of an ethnographic research that I develop since 2010 in Rio de Janeiro, in the context of which I've made some thematic interviews with young cultural producers who are slum's dwellers. Listening to their testimonies, watching their practice, I seek to understand the specificity of these activities, the qualities required to exercise them and the obstacles faced. I set my questions in the context of the centrality assumed by the field of culture as a resource, as part of the operations of urban re-qualification and in the context of the transformations that have occurred in labor market. The slums (favelas), historically considered territories of poverty and violence, are now celebrated as territories of opportunity.

Keywords: Youth. Entrepreneurship. Slums. Art and culture.

\section{Jovenes productores culturales de favela}

En este texto analizo el material recogido como parte de una investigación etnográfica que realizo desde 2010 en Río de Janeiro, en el contexto de la cual hice algunas entrevistas temáticas con jóvenes productores culturales habitantes de barrios marginales. Escuchando sus testimonios, observando sus prácticas, trato de comprender las características específicas de estas actividades, las cualidades necesarias para ejercerlas y los obstáculos que enfrentan. Sitúo mis indagaciones en el contexto de la centralidad que asume el campo de la cultura como un recurso, en el ámbito de las intervenciones de renovación urbana y de las transformaciones que se producen en el mercado laboral. Las favelas, consideradas históricamente territorios de la pobreza y de la violencia, ahora son celebradas como territorios de las oportunidades.

Palabras clave: Juventud. Emprendedorismo. Favela. Arte y cultura. 


\section{Introdução}

Em uma série de encontros organizados em 2004 para discutir o tema da inserção de jovens no mundo do trabalho, os jovens participantes, a maioria moradores da região Nordeste do Brasil e beneficiários de projetos sociais, reivindicaram o direito de ter um trabalho gratificante e do qual gostassem, um trabalho que mobilizasse capacidades e desejos; queriam que suas práticas no campo das artes e da cultura - dança, grafite, capoeira, música, teatro, poesia - pudessem dar um retorno financeiro; trabalhar sem patrão ${ }^{1}$ era um desejo recorrente (TOMMASI; NOGUEIRA; CORROCHANO, 2007). Ou seja, trabalhar com o que se gosta e se sabe fazer parecia, para muitos daqueles jovens, ser sinônimo de trabalhar com arte e cultura e como trabalhador autônomo.

Hoje, com a multiplicação de editais e cursos de formação que visam promover jovens empreendedores culturais, parece que os desejos daqueles jovens estão se concretizando. Tornar-se um trabalhador da cultura parece ser uma oportunidade aberta mesmo para os jovens moradores das periferias das cidades. Uma alternativa à falta de emprego ou ao emprego em funções subalternas que, inclusive, não parece estar sujeita à necessidade do diploma universitário para alcançar um nível de remuneração decente.

Neste artigo, traço as trajetórias de alguns jovens empreendedores culturais moradores de favelas, problematizando as características de suas atividades. Em seguida, situo a questão tanto no contexto de diferentes funções assumidas pela cultura ${ }^{2}$ quanto no âmbito de uma nova configuração do trabalho que se afirma em anos recentes, quando a figura do empreendedor adquire visibilidade. Procuro, também, mostrar como é acionado o que chamei de "dispositivo de arte e cultura" (conjunto variado de projetos, agentes, práticas) para solucionar problemas sociais. Minhas indagações situam-se no cruzamento de distintos campos disciplinares que têm como foco a juventude, a cultura, a cidade e a favela, procurando estabelecer um diálogo com a Sociologia do Trabalho.

1 Coloco em negrito as palavras e expressões utilizadas no sentido nativo, ou seja, interno ao campo.

2 O termo cultura, aqui, não faz referência ao conceito antropológico de cultura, e sim ao sentido interno ao campo da "produção cultural", ou seja, como um setor, uma atividade, um segmento específico, em que a cultura é substantivada como produto, como coisas. 


\section{Jovens empreendedores culturais de favela3}

Nos últimos anos, é comum encontrar, nas regiões da cidade onde vivem majoritariamente as camadas populares, empreendedores culturais. Jovens, geralmente participantes ou ex-participantes de projetos sociais, engajados em atividades de produção no âmbito da cultura e das artes: organizadores de saraus, realizadores de filmes, produtores de eventos artísticos e culturais. Durante a pesquisa de caráter etnográfico que desenvolvo desde 2010 no Rio de Janeiro, cujo objetivo é compreender as transformações que ocorrem nas favelas após a instalação das Unidades de Polícia Pacificadora (UPPs), acompanhei as trajetórias de alguns desses jovens, com os quais realizei algumas entrevistas temáticas (ALBERTI, 2005) com o intuito de compreender os sentidos por eles atribuídos às suas práticas e as características das atividades que desenvolvem. Acredito que essas experiências de trabalho representam um desafio tanto para as categorias geralmente acionadas no âmbito da Sociologia do Trabalho quanto no âmbito da Sociologia da Juventude.

\section{Jovem Cerebral}

Jovem Cerebral ${ }^{4}$ é o apelido de um morador do Morro da Mineira, Complexo São Carlos, uma favela incrustada no morro vizinho ao bairro boêmio de Santa Teresa. Quando o conheci, em 2011, ele tinha 37 anos, mas ainda era indicado como um jovem (e não somente pelo seu apelido).

Depois de ter vivido, na primeira infância, uma situação de violência particularmente traumática, morou em instalações da antiga Fundação do Bem-Estar do Menor. Voltou a morar no morro adolescente, na casa da avó, uma pessoa em condição de extrema pobreza. Muito revoltado com a atuação da polícia e a falta de serviços básicos no morro ("a polícia sempre como cartão de visita do poder público, nunca a Secretaria de Educação"), envolveu-se com o crime e foi preso. Foi na prisão que, ele conta, mergulhou na cultura hip hop. Sempre trabalhou organizando eventos, mesmo quando era do crime; um dia, um amigo traficante lhe apresentou André Fernandes, um jornalista engajado, por meio do qual se abriram muitas portas. Começou a trabalhar em Organizações Não Governamentais (ONGs), tornou-se vocalista, apresentou-se com o famoso funkeiro Mr. Catra e passou a fazer parte de uma banda de "eletrofunk" que faz turnê mundo afora. Mas, sobretudo, ele se tornou um agenciador do "cenário favela" para a produção de clipes de música, propagandas, filmes e documentários que procuram uma locação em alguma favela da cidade.

3 Os entrevistados tiveram acesso ao texto e concordaram em manter seus nomes verdadeiros.

4 Entrevista concedida em 3/10/2011. 
Entre outros, trabalhou nos aclamados filmes Tropa de Elite I e II.

Jovem Cerebral aciona seus contatos (ele pode contar com numerosos parceiros em quase todas as favelas da cidade) e garante o trânsito no território, procura os figurantes, assessora na escolha do figurino e até fornece indicações preciosas sobre o tipo de gíria que se fala no momento em um determinado segmento da favela. Ele ainda produz eventos culturais e procura emplacar algum projeto cultural nos editais disponíveis. Na literatura especializada, poderia ser considerado um exemplo típico de "resiliente", de alguém que consegue capitalizar os conhecimentos adquiridos na adversidade. Se a favela está na moda, como ele diz, ele procura fazer com que não somente os de fora possam lucrar com essa moda, e sim também os agentes de dentro. Criou uma empresa, chamada Favela Negócios e Consultorias e uma ONG, por intermédio das quais organiza eventos culturais em diversos bairros da cidade. Eventualmente trabalha como consultor de algum programa de governo, na área da juventude.

\begin{abstract}
"A favela é muito rica em cultura, cultura de diversas formas: tem uma cultura econômica paralela, tem uma cultura literal e essas coisas acabam influenciando a cidade como um todo, porque o Rio de Janeiro é uma grande favela e acaba contaminando toda essa sociedade. O funk é um exemplo disso, a forma das pessoas se vestirem tem muito a ver com o que as meninas da favela vestem, porque as meninas da Zona Sul vão para o baile no morro aí veem, querem comprar também, então a favela exporta cultura, exporta comportamento, exporta língua" (Jovem Cerebral).
\end{abstract}

Assim, Jovem Cerebral experimentou há bastante tempo a ideia de que favela é oportunidade, ${ }^{5}$ argumentando que, ao contrário do que geralmente se pensa, a motivação para os jovens entrarem no crime não é econômica, mas social.
"A minha estada no crime era, em certa maneira, em busca dessa mesma coisa que estou buscando hoje no hip hop, só que só tive a oportunidade de ter isso na criminalidade e agora eu mudei esse foco, estou em busca de transformação social, transformação cultural" (Jovem Cerebral).

Provavelmente, a trajetória dele se encaixa bem na imagem do empreendedor por oportunidade desenhada pelo Serviço Brasileiro de Apoio às Micro e Pequenas Empresas (Sebrae), entidade bastante atuante nas comunidades do Rio de Janeiro após a instalação das UPPs: aquele que sabe identificar, em seu entorno, a brecha, o território fértil para abrir seu negócio; diferentemente do empreendedor por necessidade, para o qual o negócio próprio não é resultado de uma escolha intencional motivada pela capacidade de colher a oportunidade, e sim a consequência do desemprego, da necessidade de ganhar dinheiro. Na visão do

5 Título de um programa e de uma série de publicações organizados pelo Fórum Nacional/Instituto Nacional de Altos Estudos (disponível em: <www.forumancional.org.br >), entidade presidida pelo ex-ministro João Paulo Velloso, no Rio de Janeiro pós-pacificação. 
Sebrae, é o primeiro tipo de empreendedor que tem que ser valorizado e incentivado, enquanto pode fazer a diferença no âmbito do desenvolvimento econômico do país (GEM, 2013).

\section{Jovens produtores culturais da CDD}

Na Cidade de Deus (CDD), território da Zona Oeste da cidade do Rio de Janeiro onde desenvolvo, ${ }^{6}$ há mais de quatros anos, uma pesquisa de caráter etnográfico, há vários exemplos de jovens produtores culturais.

Marcio 7 mora em um dos setores mais pobres da favela, mais afastado da avenida que delimita a fronteira da CDD com o asfalto; o lugar onde ainda há tiroteios, apesar de a CDD ter sido o segundo território da cidade em que se instalou uma UPP, em 2009. Ele começou a frequentar os projetos sociais promovidos pela Igreja Católica local, uma igreja politizada, como ele diz, quando tinha 15 anos. Foi da Pastoral de Favelas e frequentou vários cursos de formação política. Passou por vários projetos promovidos pelas ONGs da cidade ligadas à trajetória de engajamento político da Igreja Católica. Seu percurso é, assim, bastante típico dos militantes das camadas populares até os anos 1990. Mora com a mãe, dona de casa, e o irmão, técnico de telefonia. O pai, hoje falecido, era um faz tudo: pedreiro, encanador, porteiro. Quando o conheci, no final de 2010, Marcio tocava com alguns amigos em uma banda de rock e trabalhava como voluntário em uma organização local, por meio da qual mantinha um envolvimento crítico com as organizações comunitárias, depositárias de uma história significativa de lutas políticas. Muito crítico, desencantado com os vários agenciadores que aparecem na favela, Marcio é um jovem que tem muitos conhecimentos e a sabedoria de quem passou por diferentes experiências e aprendeu com elas. Desde que o conheço tento convencê-lo a se preparar para entrar na faculdade, mas ele resiste, um pouco por preguiça de ter que estudar para a prova, um pouco porque sua trajetória profissional, até o momento, é uma trajetória de sucesso que não depende (e talvez não seria afetada) da posse de um título universitário.

Seu percurso teve uma inflexão quando ele foi contratado como articulador local pela Agência de Redes para Juventude, ${ }^{8}$ um projeto social que começou a operar na

6 A aluna Dafne Velazco é uma parceira importante da pesquisa de campo. Minhas informações sobre o perfil dos jovens produtores culturais são complementadas pelas recolhidas por ela (VELAZCO, 2014).

7 Fizemos várias entrevistas com Marcio. Para este artigo faço referência especificamente a duas conversas que gravei com ele e Lúcio, nos dias 13/10 e 12/11/2014.

8 O ponto de partida da agência é o desejo dos jovens e a crença que eles são potentes. O projeto pretende fornecer ferramentas, instrumentos, técnicas de gestão - ou, no léxico da agência, repertório - para que os jovens possam desenvolver sua subjetividade (VELAZCO, 2014). Mais informações em: <www.agenciarj.org>. 
favela após a pacificação. Sua rede de contatos ampliou-se e ele começou a circular por muitos espaços de produção artística na cidade. Hoje trabalha como freelancer e produtor cultural, na produção de vídeos e organização de eventos. Continua engajado na organização local em que, dependendo da disponibilidade de recursos, trabalha como voluntário ou como técnico assalariado.

Ricardo ${ }^{9}$ é ator e ganhou o primeiro prêmio ${ }^{10}$ na primeira edição do curso da Agência de Redes, com o projeto Conexões Culturais, cuja proposta era organizar aos domingos um evento de poesia, teatro e circo, em que os artistas da CDD - aqueles não ligados ao funk ou ao pagode, estilos considerados "hegemônicos" na favela pudessem mostrar seus talentos. Mora com a mãe, auxiliar de enfermagem, em uma casa situada na região central da CDD, mais próxima do asfalto; tem um filho que não mora com ele. Como todos os meus jovens interlocutores, sempre estudou em escolas públicas da região. Mesmo assim, foi na escola que frequentou o primeiro curso de teatro; de lá passou para o curso oferecido pela Central Única das Favelas (Cufa), ONG promovida pelo rapper MVBill, e por vários outros cursos de formação do ator. Desde cedo, deu aula de teatro e, em 2011, tornou-se Parceiro do RJ, um quadro da RJTV, emissora da Rede Globo, no qual jovens moradores de favelas realizam reportagens sobre esses lugares.

De todos, Ricardo é sem dúvida o mais bem-sucedido. Foi consultor de importantes programas da Rede Globo, atua em spots publicitários de grande veiculação e em peças que se apresentam nos teatros da cidade frequentados pelas elites. Sua companhia de teatro está sediada em um espaço cedido pela Prefeitura. Pela forma como os moradores dirigem-se a ele, frequentemente se orgulhando por conhecêlo desde criança, percebo que ele conquistou um lugar de visibilidade e respeito na comunidade.

Durante uma de nossas conversas, Ricardo expressa uma visão bem crítica sobre os "usos da cultura", questionando o que se tornou a única alternativa ("o que sobrou") para os jovens moradores de favela que querem escapar do destino desde sempre reservado para eles: tornar-se bandido ou mão de obra barata (TOMMASI, 2012).

Não dá para a agência abraçar todas as potências, mas tem que ver outros projetos que desenvolvam outros tipos de potências que têm nas favelas, a potência do arquiteto etc., não só por meio da cultura, senão fica... Como diz um amigo meu, "pô cara, os caras querem falar que favelado samba bem, dança bem, canta bem. Meu irmão, foi o que sobrou!". Não tem como, sobrou para a gente e a gente vai mandar mal? Sobrou isso, cultura e arte, que é uma parada meio abstrata. Mas uma coisa mais exata ninguém fala que manda bem: "preto manda bem na Matemática", "preto arrebenta na Medicina"; cara, o que precisa agora é dar a possibilidade para que ele

9 A entrevista com Ricardo foi realizada por Dafne Velazco (VELAZCO, 2014).

10 A agência oferece aos jovens uma bolsa de $\mathrm{R} \$ 100,00$ por mês para frequentar um Ciclo de Estímulos e elaborar, ao final, um projeto de intervenção sociocultural em seu território. Alguns deles são premiados com $R \$ 10.000,00$ para colocá-los em prática. 
mande bem em outras coisas também (VELAZCO, 2014).

Lúcio é bailarino, dá aula de dança em algumas escolas da região e na mesma organização local em que trabalha Marcio. Tem uma companhia de dança para manter, em que escreve projetos para concorrer a editais. Narra que demorou bastante para ele poder assumir, no âmbito familiar, sua vontade de ser artista. Há pouco tempo, passou a se reconhecer como produtor cultural, sobretudo a partir de seu envolvimento na organização do Unificarte, um encontro no palco de diversos grupos de dança oriundos dos subúrbios e das favelas da cidade, evento promovido há três anos no âmbito da organização local. Lucio tem 33 anos e mora com a esposa, manicure e trabalhadora autônoma, e a filha pequena, na casa da sogra.

\section{Trabalhadores da cultura}

Como caracterizar essa forma de trabalho? O que significa para esses jovens ser "trabalhador da cultura"? As observações realizadas em campo e o material coletado por meio das entrevistas temáticas permitem-me arriscar, aqui, algumas hipóteses iniciais, que poderão orientar futuras e mais sistemáticas indagações.

Uma primeira observação é sobre a indiferenciação entre experiências, tempos e lugares, geralmente mantidos (e estudados) como distintos: trabalho, ativismo político, lazer, arte, diversão, lugar de moradia e espaço de trabalho são, na experiência desses jovens, completamente misturados ${ }^{11}$

A imbricação entre trabalho e militância já é perceptível nas trajetórias de jovens engajados em projetos sociais como educadores, gestores, articuladores locais. Como já argumentei (TOMMASI, 2014), a implicação dos operadores nativos e a territorialização das ações são estratégias que caracterizam as transformações ocorridas no decorrer dos anos 1990 na abordagem da chamada "questão social", ou seja, o enfrentamento de problemas sociais via realização de projetos operados pelas entidades do terceiro setor. Conhecer o local, circular entre os diferentes segmentos (o associativismo, os agentes governamentais, o tráfico), conhecer a gíria, o "procedê", os interditos, poder bater em todas as portas e saber com quem se está falando no complexo mundo das relações sociais nas favelas e periferias das cidades tornaram-se recursos importantes que os jovens podem acionar para serem contratados no âmbito de um projeto. Podemos chamar esse de um "capital favela". O articulador local é uma figura de trabalhador à qual recorre, na atualidade, a maioria dos projetos. Pesquisadores, gestores, coordenadores de projetos precisam

11 Assim como, muitas vezes e sempre mais, ser artista e produtor, questão que não vou explorar neste trabalho enquanto remete a uma outra discussão sobre o mercado da arte, as características dos artistas contemporâneos e da produção dita independente. 
do apoio desses "nativos" para poder entrar, se movimentar, coletar informações. O articulador não tem autonomia com relação a seus superiores e, em termos financeiros, seu trabalho não é muito reconhecido (geralmente ganha um salário mínimo); mas, no âmbito local, pode gozar de bastante prestígio por ser identificado como o representante local das entidades de fora.

Outra característica importante: na opinião de meus interlocutores, o trabalho para eles é uma forma de lazer - gostam do que fazem e não trocariam isso por nada. A divisão entre trabalho e tempo livre não parece fazer sentido para eles.

Cabe ressaltar que, como mostra a trajetória do Jovem Cerebral, a existência de produtores culturais na favela não é de hoje. Sempre houve essas figuras, em particular os produtores de bailes funk, muitas vezes ligados ao mundo do crime, que supria as faltas de serviços públicos e de lazer.

Indaguei:

- Você acha que tem mais gente hoje produzindo na favela?

Marcio respondeu:

- Acho que sempre teve, mas hoje tem um movimento de se perceber enquanto produtor. Antes o cara estava produzindo um baile funk, mas não sabia que estava fazendo produção.

Esse autorreconhecimento é consequência, provavelmente, da valorização social atual das profissões ligadas à cultura e à criatividade, como argumentarei ao longo do texto. Especificamente, no Rio de Janeiro, houve um investimento, após a instalação das UPPs, na profissionalização de jovens como produtores culturais para suprir a falta dos produtores ligados ao tráfico. Motivada, inclusive, pela criminalização dos bailes funk (em que se toca o chamado funk proibidão) e a vontade de moralizar essa expressão musical por meio da difusão do chamado funk do bem (ou funk de raiz, denominação que remete à ideia de que o funk foi contaminado pelo crime e o mercado, e agora sua essência deveria ser resgatada, enquanto expressão da cultura afro, da identidade dos jovens de favela, da contestação ao sistema opressor).

Assim, no Rio de Janeiro dos megaeventos e da pacificação multiplicaram-se os debates sobre o papel da arte e da cultura, as oficinas e cursos que visam ensinar a escrever projetos para concorrer aos (ainda bem poucos) editais disponíveis para financiar esse tipo de produção. A existência de editais, mesmo se o volume de recursos é extremamente limitado se comparado aos recursos investidos nas grandes produções da cidade (como a Virada Carioca) estimula, sem dúvida, a atuação desses produtores.

Quais são as qualidades de um bom produtor cultural? Quando pergunto para 
meus interlocutores, me respondem sem titubear: tem que ficar antenado. Tem que ser proativo, palavra muito difusa atualmente no circuito do trabalho social que, como muitas outras, provém do mundo empresarial. A insistência é sobre a necessidade de romper com a suposta passividade, considerada a condição típica dos subalternos. Para meus interlocutores, estar ligado significa correr atrás, não ficar parado, ficar plugado na internet 24 horas por dia para poder colher rapidamente as oportunidades: publicação de editais, chamadas para reuniões, convocações variadas, contatos.

Ampliar a rede é outra injunção importante, que implica circular muito, participar de muitas reuniões e de muitas conversas informais, em qualquer horário e dia da semana. Circular pelos inúmeros eventos que acontecem na cidade, ligados ao circuito cultural. Neste sentido, parece-me que meus interlocutores não se enquadram nos conceitos ainda bastante utilizados no âmbito das Ciências Sociais para analisar a questão urbana: eles não são nem segregados nem marginalizados. Mesmo assim, continuam ocupando, no circuito da produção cultural da cidade, um lugar periférico. Eles têm clareza de que, nesse circuito, o dinheiro é decididamente concentrado nas mãos de (poucas) grandes produtoras. Além disso, os editais aos quais têm acesso geralmente exigem realizar produções restritas aos territórios das favelas. Como eles dizem, "é difícil disputar a cidade".

Marcio explicita que há um rótulo que deve ser combatido: "os produtores de favela sempre são jogados no âmbito das ONGs, da necessidade de se fazer alguma coisa social". Ou seja, arte e cultura são consideradas meios para (o desenvolvimento local, a saída de jovens do tráfico, a valorização da identidade), e não fins em si mesmas.

A visibilidade acontece quando agentes externos (poder público, mídia, Academia) procuram acionar um novo regime discursivo sobre a favela, argumentando sobre sua potência (contraposta à ideia de carência com a qual esses territórios foram historicamente estigmatizados), ou para ilustrar a valorização da diversidade na cidade ou mostrar novas formas de engajamento político dos jovens. A retórica dessas representações não pode fazer esquecer que os jovens negros moradores de favelas e periferias das cidades são as principais vítimas de assassinatos. Aliás, o fato de ser artista não garante escapar a esse destino, como provam o recente assassinato de DG, bailarino do Programa "Esquenta" da Rede Globo ou, em 2010, de Gambá, conhecido dançarino do Passinho.

Outro fator que impede o crescimento desses produtores diz respeito ao seu enquadramento jurídico: muitos editais requerem que o produtor seja registrado como Microempresa (ME) ou como Microempreendedor Individual (MEI), o que significa que não pode faturar mais do que $\mathrm{R} \$ 60.000,00$ por ano.

$\mathrm{Na}$ fala de meus interlocutores, a formação é bastante valorizada, mas não uma formação geral, como uma faculdade de produção cultural, e sim cursos pontuais e específicos (curso de iluminação, cenografia, edição, câmera). O trabalho aprende-se 
na prática, e não na teoria. Mas, por outro lado, a faculdade é um bom lugar para se fazer contatos, para ampliar a rede.

Outra queixa é que "a informação sobre os editais circula pouco". Há, neste sentido, um mercado da informação (que, talvez, confunde-se com o clientelismo político) cujo funcionamento merece ser melhor explorado.

Uma condição apontada como negativa é que você "trabalha sozinho, não tem uma equipe, um assistente". Raros são os que conseguem criar e manter um coletivo (apesar da difusão desse termo no debate sobre as novas formas de engajamento político-social-cultural dos jovens).

A remuneração não parece ser um atrativo significativo para esses jovens que ganham, em média, um pouco mais de um salário mínimo. De fato, eles andam muito, trabalham muito, fazem vários bicos ao mesmo tempo, não podem contar com um salário fixo e, por causa disso, dificilmente podem assumir, sozinhos, as contas de uma casa.

Então, o que os atrai nesse tipo de atividades? A ideia de "trabalhar com o que gosto", de se inserir no restrito (e elitista) mundo da arte e cultura, de não se submeter à tirania de um patrão? De se relacionar com pessoas, frequentar lugares, estabelecer redes bem mais amplas do que a favela? São questões que orientam minha pesquisa. Uma frase do Marcio condensa os atrativos: "para mim esse trabalho é também um pouco diversão. Eu faço meu tempo. A gente é criador". Indistinção entre trabalho e lazer, autonomia, criatividade. As últimas duas são características enfatizadas na literatura sobre empreendedorismo, como veremos a seguir.

"Há muitas profissões onde você não cria, você só é executor. Na produção cultural você pode ser criador, fazer coisas novas, inovar, pode fazer uma intervenção cultural, não existe um formato de produção, existe o que o formato do edital pede, mas o projeto que você vai fazer, o tipo de evento é você que faz" (Marcio).

Há, também, um sentido e uma busca forte pela autorrealização.

\begin{abstract}
"Você convoca 20 grupos para participar de um festival; sou eu quem entra em contato com todos os grupos, todos que eu conheço. E quando você vê que está em cima e três ou quatro grupos desistem de ir, é uma dor de cabeça! Essas são as dores de cabeça que têm no decorrer, mas quando você chega no final e você vê que foi um sucesso, todo esse esforço que você fez durante um ano para realizar aquilo, é espetacular, não tem igual" (Lucio).
\end{abstract}

Sem dúvida, as trajetórias desses jovens são distintas daquelas da geração de seus pais, centradas na realização do sonho da casa própria, na preocupação com a poupança e a consolidação da estrutura familiar. Hoje, estes jovens casam tarde, demoram mais para ter filhos, moram com os pais bem depois de ter cumprido 30 anos e depois de ter casado. Esses marcadores (casar, ter filhos, manter seu próprio 
lar, ingressar no mercado de trabalho) que, antigamente, definiam a entrada na vida adulta, não são os que definem suas trajetórias de vida e profissionais. Inclusive, muitas vezes não ter filhos é uma condição quase que indispensável para se manter nessa profissão. Muitos jovens, quando se tornam pais, precisam desistir e correr atrás de um trabalho que garanta uma remuneração estável; as opções, nesses casos, são bastante restritas, para alguém que não tem curso superior nem experiência de trabalho: peão de obra, trabalhador de call center ou segurança privado, algo muito distante da produção cultural. Foi o que aconteceu com alguns de nossos interlocutores, outros egressos do projeto da Agência de Redes (VELAZCO, 2014; TOMMASI, 2015).

Um atrativo importante diz respeito ao sonho da autonomia: trabalhar sem patrão, fazer os próprios horários. Mesmo que isso signifique, como diz Lucio, "trabalhar muito em casa, e as pessoas brigam com você por causa disso". Efeito da indistinção entre o ambiente da casa e o lugar do trabalho. Mesmo assim, eles preferem trabalhar como autônomos e não ir trabalhar para uma grande produtora. Preferem sonhar com ter sua própria produtora. Ou seja, o trabalho assalariado não é um valor, uma meta. Pelo menos enquanto "dá para pagar as contas" (e o valor das contas a pagar permita). Porque "na produtora você trabalha nos projetos da produtora, não no seu projeto". Se a vida no âmbito do novo espírito do capitalismo (BOLTANSKI; CHIAPELLO, 2009) virou uma sucessão de projetos, ter o próprio projeto é uma qualidade bastante valorizada.

Parece-me que para compreender o significado adquirido por essa forma de trabalho é preciso situá-la tanto no âmbito da centralidade assumida pelo campo da cultura na contemporaneidade quanto no contexto das transformações ocorridas no mundo do trabalho. Na última parte do texto, vou apresentar rapidamente esses argumentos.

\section{A performance da cultura}

Foi o mundo da cultura que primeiro aceitou o desafio de mudar. De criar um outro Brasil. Sem pobreza e sem a arrogância dos ricos, sem miséria definitivamente. É pela brecha da cultura que poderemos dar o salto do reencontro do país com sua cara. Um Brasil totalmente simples, mas radicalmente humano. O que importa é alimentar gente, educar gente, empregar gente. E descobrir e reinventar gente é a grande obra da cultura (MAMBERTI apud BRANT, 2003, p. 15).

Recurso para o desenvolvimento, setor prioritário para os investimentos, ingrediente central nos projetos de requalificação urbana, solução para os problemas sociais: o campo da cultura assumiu, em anos recentes, novos e estratégicos papéis. No Brasil, as palavras acima do então secretário da Identidade e Diversidade Cultural do Ministério da Cultura (MinC), Sergio Mamberti, exemplificam bem o 
entusiasmo com o qual a gestão de Gilberto Gil à frente do MinC reivindicou o papel transformador que se esperava ser a marca do primeiro governo do Partido dos Trabalhadores (PT) no âmbito federal. Para ele, por meio da "brecha da cultura", o combate à pobreza, a gestão participativa e o respeito e a valorização da diversidade seriam as marcas da criação de um "outro Brasil".

Manuel Delgado, que analisa as transformações urbanísticas e arquitetônicas ocorridas na cidade de Barcelona, pioneira em empreender grandes projetos de requalificação urbana, chama atenção para a representação da cultura como valor incontestável, acionada no contexto desses projetos, "una instancia em certo modo sobrehumana a cuyos efectos asignarle virtudes poco menos que salvíficas" (DELGADO, 2008 , p. 6). São essas supostas "virtudes salvadoras" da cultura que operam, como argumentarei a seguir, nos atuais agenciamentos dos jovens moradores de favelas.

No Rio de Janeiro, são evidentes as funções assumidas pela cultura no âmbito dos projetos de requalificação urbana, incluindo a valorização temática de algumas regiões da cidade. Os projetos investem, também, na renovação e na projeção de uma identidade nacional via instalação de museus (fechados, como o Museu do Mar, ou a céu aberto, como o do Morro da Providência) e a patrimonialização de algumas atividades (os vendedores de biscoitos Globo na praia, a capoeira), ao mesmo tempo comerciais e culturais.

\section{Cultura como recurso e economia criativa}

Para George Yúdice, no mundo globalizado, o papel da cultura expandiu-se como nunca antes para as esferas econômicas e políticas. Os organismos multilaterais e a União Europeia "começam a compreender a cultura como esfera crucial de investimentos, a cultura e as artes são cada vez mais tratadas como qualquer outro recurso" (YÚDICE, 2006, p. 30). Na atual fase do capitalismo as novas tecnologias, o trabalho imaterial, os bens culturais adquirem centralidade para o crescimento econômico. É a fase do "capitalismo cultural" (RIFKIN apud YÚDICE, 2006, p. 25). Da esfera econômica à esfera política, essa "conveniência da cultura" transforma a cultura em recurso para outros fins, a produção cultural em produção econômica e politicamente relevante.

A cultura tornou-se central também no âmbito do processo de valorização das diferenças que, segundo o autor, é parte da globalização. A diferença tornou-se um valor, acionando uma suposta valorização da identidade de minorias culturais. $A$ reivindicação de especificidades e diferenças culturais é "conveniente", na medida em que multiplica mercadorias e confere direitos às comunidades. "Qualquer produto pode ser saturado de identidade”, observa Paul Gilroy (GILROY, 2007, p. 124). 
No Brasil, definições identitárias são acionadas para ordenar as diversidades às quais está direcionado o cardápio de projetos da Secretaria da Identidade e Diversidade Cultural do MinC. Os critérios de classificação são curiosamente muito variados: etários (jovens), étnicos ou raciais (indígenas, negros), de orientação sexual ou identidade de gênero (gay, trans), de localização (rurais, periféricos) e outros (pessoas com deficiência, doentes mentais).

Grupos minoritários são supostamente provedores de experiências fundamentais na construção de ambientes criativos. A categoria economia criativa, ${ }^{12}$ que se populariza no começo do novo século, pode ser definida como o setor da economia em que a criatividade dos indivíduos é a matéria-prima geradora de valor. Os setores econômicos incluídos nessa nomenclatura variam conforme os países e as instituições. O governo do estado do Rio de Janeiro, alinhando-se à United Nations Conference on Trade and Development (UNCTAD), define 14 segmentos criativos que vão da arquitetura ao design, das artes ao mercado editorial, da pesquisa à publicidade. Segundo a UNCTAD, o crescimento desse setor econômico nos países desenvolvidos é acima do crescimento médio do Produto Interno Bruto (PIB) (SEBRAE, 2012, p. 11).

\section{Cultura e requalificação urbana}

Para a urbanista Otilia Arantes, os novos paradigmas de gestão do espaço urbano propostos pelo chamado "planejamento estratégico" estão centrados na proposta de requalificação dos espaços por intermédio do que ela denomina de "iscas culturais".

Quando, nos dias de hoje, fala-se de cidade, fala-se cada vez menos em racionalidade, funcionalidade, zoneamento, plano diretor etc. e cada vez mais em requalificação [...]. A ênfase deixa de estar predominantemente na ordem técnica do plano para cair no vasto domínio passe-partout do assim chamado "cultural" e sua vasta gama de produtos derivados (ARANTES, 2012, p. 13).

Esse "culturalismo de mercado" opera por meio da realização de "macroiniciativas urbanísticas" a cargo de famosos estúdios de arquitetura (que, aliás, são sempre os mesmos): no Rio de Janeiro, as obras do Porto Maravilha abrigam o Museu de Arte do Rio (MAR), o Museu do Amanhã (anunciado como "uma nova geração de museus de ciências") ${ }^{13}$ e o que poderíamos chamar de "isca cultural-identitária", ou seja, a criação do Circuito de Celebração da Herança Africana, do qual fazem parte

12 Existe uma vasta bibliografia sobre o tema. Uma boa síntese sobre o ponto de vista econômico é aquela realizada pelo Itaú Cultural na publicação "Economia criativa como estratégia de desenvolvimento: uma visão dos países em desenvolvimento" (REIS, 2008).

13 Disponível em: <museudoamanha.org.br>. 
a revitalização dos Cais do Valongo e da Imperatriz e a Pedra do Sal (considerada o berço do samba). ${ }^{14}$ Desta forma, a intervenção urbanística na região central visa transformá-la no símbolo da celebração de uma cultura afro, purificada de seus elementos religiosos.

Em 2014, no âmbito da organização das comemorações dos 450 anos da cidade do Rio de Janeiro, foi lançado, pela Secretaria Municipal de Cultura, um edital cujos propósitos exemplificam muito bem essas funções assumidas pela cultura. O edital pretende "promover a valorização e o conhecimento acerca da memória dos símbolos da cultura popular carioca, além de celebrar a história do Rio, de seus personagens [...], de seu patrimônio material e imaterial" (RIO DE JANEIRO, 2014, p. 1). Para fazer isso, serão financiadas 85 ações locais promovidas por pessoas físicas ou Empreendedores Individuais.

Entende-se por "ação local" a realização continuada de práticas, atividades e projetos nos campos da cultura, da arte, da comunicação e do conhecimento que promovam transformações socioculturais positivas nas comunidades e nos territórios em que são desenvolvidos [...]. As ações locais deverão estimular o exercício da cidadania e fomentar a diversidade da cultura carioca, nas suas expressões populares, urbanas e tradicionais. As ações locais deverão contemplar prioritariamente pessoas em situação de pobreza; vítimas de violência; em situação de rua; em situação de restrição e privação de liberdade/população carcerária; com deficiência; em sofrimento físico e/ou psíquico; mulheres, gays, lésbicas, bissexuais, travestis, transgêneros e transexuais; crianças, jovens, idosos; povos e comunidades tradicionais; negros, ciganos e indígenas (RIO DE JANEIRO, 2014, p. 1-2).

Os propósitos normativos da proposta são evidentes: as ações devem promover transformações, ou seja, não podem ser desinteressadas, e estas transformações devem ser positivas, segundo parâmetros de positividade que dizem respeito ao "estimulo à cidadania e à diversidade cultural". Essa diversidade inclui, seletivamente, expressões populares, urbanas e tradicionais enquanto expressões a serem valorizadas. Por fim, a lista de populações prioritárias é longa, mas inclui tanto populações consideradas em risco (pobres, vítimas de violência, em situação de rua, privados de liberdade, deficientes) quanto identidades específicas (mulheres, gays, lésbicas, bissexuais, travestis, transgêneros e transexuais), misturadas com minorias (povos de comunidades tradicionais, negros, ciganos e indígenas) e distinções geracionais (crianças, jovens, idosos). Todas estas são contidas em uma expressão em voga: a valorização da diversidade.

\section{O dispositivo de arte e cultura e as favelas criativas}

Se a cultura, como notado por Delgado, assume funções "salvadoras", estas podem

14 Disponível em: < portomaravilha.com.br>. 
ser colocadas a serviço da "salvação" dos sujeitos-problema que corporificam, no imaginário social, o medo da violência: os jovens negros moradores das regiões periféricas, em particular, no Rio de Janeiro, das favelas. Assim, a partir dos anos 1990, projetos empreendidos por organizações governamentais propõem-se a oferecer a estes jovens, como alternativa ao tráfico, cursos de formação (ou melhor, de capacitação) no âmbito de um indiferenciado campo da arte e cultura: vídeo, dança, música, grafite, teatro. Um conjunto variado de projetos, agentes, práticas que conformam o que chamei de dispositivo arte e cultura substitui os tradicionais cursos de profissionalização, com o intuito de ocupar o tempo ocioso e disputar os jovens com o tráfico, para que eles se tornem trabalhadores e não bandidos.

Essa proposta de cultura como antídoto, que retoma a função civilizadora da cultura, é levada a cabo por algumas ONGs que monopolizam um volume significativo de recursos. Recentemente esse dispositivo é acionado também pela Secretaria de Cultura do governo do estado. No âmbito do programa Favela Criativa, a Secretaria lançou o projeto Formação de Jovens Agentes de Cultura, cujo objetivo é "capacitar 700 jovens para que se tornem empreendedores culturais, tendo melhores condições de concorrer a editais de incentivo à cultura". Explicitamente, a produção cultural é entendida como negócio: "o projeto irá beneficiar jovens com o prêmio de $\mathrm{R} \$ 12.000$ para que coloquem em prática seu negócio cultural".15

Cabe lembrar que o recurso à cultura para solucionar problemas sociais não é uma invenção brasileira. George Yúdice comenta sobre o uso utilitarista da arte e cultura nos Estados Unidos: "melhorar a educação, abrandar a rixa racial, ajudar a reverter a deterioração urbana através do turismo cultural, criar empregos, diminuir a criminalidade [...]. Os artistas estão sendo levados a gerenciar o social" (YÚDICE, 2006 , p. 29). Segundo ele, o envolvimento de artistas em projetos sociais ocorreu em consequência da crise do estado social, ou seja, da falta de recursos públicos para investir em programas sociais.

\section{Do culto da performance ao empreendedorismo}

O sociólogo francês Alain Ehrenberg analisa as transformações ocorridas no mundo do trabalho e suas consequências sobre a subjetividade dos trabalhadores (EHRENBERG, 2010). Para o autor, a partir dos anos 1980, o esporte tornou-se o modelo de performance a ser emulado no mundo empresarial, na esfera da vida pública e privada: o esporte é um estilo de vida, um estado de espírito, o gosto do desafio e da aventura, trabalha conjuntamente a dimensão da justa desigualdade, baseada na

15 Mais informações em: <http://www.favelacriativa.rj.gov.br/inscricoes-para-formacao-de-700-jovens-agentesde-cultura/>. 
competição, e da imprevisibilidade do risco, essencial à aventura. O esporte "é um sistema de condutas de si que consiste em implicar o indivíduo na formação de sua autonomia e de sua responsabilidade" (EHRENBERG, 2010, p. 18). O empreendedor é a figura heroica que condensa essas características, em uma sociedade que faz da concorrência interindividual uma justa competição.

Quando a salvação coletiva, que é a transformação política da sociedade, está em crise, a verborragia de challenges, desafios, performances, de dinamismo e outras atitudes conquistadoras constitui um conjunto de disciplinas de salvação pessoal. [...] o mito prometeico do homem sozinho no barco ${ }^{16}$ do seu destino e confrontado com a tarefa de ter de se construir, encontrar para si próprio, e por si mesmo, um lugar e uma identidade sociais torna-se um lugar comum. Numa relação com o futuro caracterizada pela incerteza, que vê recuar, em nome da mudança permanente, a crença no progresso linear que simbolizava o Estado-providência, a ação de empreender é eleita como o instrumento de um heroísmo generalizado. É por isso que o sucesso empreendedor é considerado como a via real do sucesso (EHRENBERG, 2010, p. 13).

A narrativa esportiva rompe com a moral disciplinar da submissão a interesses superiores (patronais), dando lugar a uma "liberação que se impõe a si em nome de si mesmo" (EHRENBERG, 2010, p. 23). Além disso, o heroísmo esportivo está ao alcance de todos, não é apanágio de uma elite: "ao destino de uma elite se substitui uma história possível para todos" (op. cit., p. 30).

Da mesma forma, Boltanski e Chiapello em "O novo espírito do capitalismo" analisam a literatura de gestão empresarial e identificam uma inflexão ocorrida nos anos 1990, quando se exige um novo tipo de trabalhador: engajado, motivado, flexível, adaptável, criativo, envolvido afetivamente com seu trabalho. O controle passa a ser exercido por meio da existência de relações de confiança e afetividade, que substituem a impessoalidade das relações como base de uma "verdadeira autonomia" (BOLTANSKI; CHIAPELLO, 2009, p. 122). Ao mesmo tempo, a organização do trabalho por carreiras hierárquicas é substituída pela sucessão de projetos, o que desmantela as garantias trabalhistas, responsabilizando os trabalhadores por sua empregabilidade, por meio da capacidade de gerir seu "capital pessoal". No caso, nossos jovens empreendedores culturais de favela acionam, como vimos exemplarmente no caso do Jovem Cerebral, seu "capital favela". Para Boltanki e Chiapello, o homem do terceiro espírito do capitalismo seria o indivíduo empreendedor.

Avaliar as consequências da recente difusão do empreendedorismo, no Brasil, mais além da precarização das relações de trabalho, representa um desafio para as pesquisas. Já em 2002, o sociólogo Luis Antonio Machado da Silva chamou atenção para a difusão de uma nova cultura de trabalho, muito distinta daquela

16 Muitos filmes, nos últimos anos, retrataram situações de "homens sozinhos no barco de seu destino", inclusive a saga infantil "As aventuras de Pi". 
do assalariamento, que "fere de morte os valores da solidariedade" (SILVA, 2002, p. 105). O par empregabilidade/empreendedorismo "aponta para novos modos de exploração capitalista, cuja característica mais fundamental é a individualização e a subjetivação dos controles que organizam a vida social" (op. cit., p. 101). Esses "batalhadores brasileiros" (SOUZA, 2010) trabalham muito, ganham pouco, concorrem permanentemente entre si e, muitas vezes, são, ao mesmo tempo, patrão e empregado.

André Singer, em seu livro sobre o lulismo (SINGER, 2012) argumenta sobre a ampliação da camada dos pequenos empreendedores, que seriam a maioria do que o economista Marcelo Neri chama de "nova classe média" (NERI, 2011). Outro economista, Marcio Pochmann, oportunamente discute esse conceito: não se trata de classe média, e sim de trabalhadores precários (POCHMANN, 2011). Os dois concordam sobre o fato de que essa nova classe trabalhadora não se integra ao velho modelo do sindicalismo e da luta coletiva.

Vale lembrar que empreendedorismo é um termo difundido pelo economista Schumpeter nos anos 1950, para indicar as características de espírito do homem de negócios adequadas à "destruição criadora" que possibilita, segundo ele, a expansão do capitalismo: inovador, criativo, disposto a assumir riscos, capaz de aproveitar as oportunidades. Inovação, criatividade, ousadia, superação são as qualidades enfatizadas, hoje em dia, como características do empreendedor de sucesso.

Com esse espírito, cursos de formação sobre empreendedorismo ${ }^{17}$ foram introduzidos no Brasil durante os anos 1990, em particular dirigidos aos jovens. $\mathrm{Na}$ atualidade, a difusão do termo e das práticas de apoio ao empreendedorismo tornouse massiva. Programas de rádio, de televisão, cursos, palestras e sites nos incitam, nos aconselham, nos fornecem receitas para ter sucesso com o nosso empreendimento, qualquer que seja.

Podemos avançar à hipótese de que o empreendedorismo substitui, na atualidade, o incentivo à poupança, que serviu, no século XIX, como mecanismo de gestão das populações pobres, transformando o direito político em moralidade econômica (EWALD, 1986). Os valores da poupança e do esforço individual agora são substituídos, ou melhor, complementados, pelos valores da inovação, da criatividade, da ativação e da incerteza permanentes. Há, na ênfase atual sobre o empreendedorismo, algo que modifica a forma como a pobreza é gerida: os comportamentos dos pobres não devem ser mudados porque são considerados antieconômicos, e sim reforçados, enquanto considerados os mais adequados ao espírito empreendedor. O pobre é, por definição, empreendedor, e só resta estimular

$17 \mathrm{Na}$ esteira da Organização para a Cooperação e o Desenvolvimento Econômico (OCDE), o Instituto Brasileiro de Geografia e Estatística (IBGE) resolveu padronizar a definição de empreendedor: "são pessoas, necessariamente donos de negócios, que buscam gerar valor por meio da criação ou expansão de alguma atividade econômica, identificando e explorando novos produtos, processos e mercados" (IBGE, 2012, p. 9). 
e reforçar sua criatividade, que lhe permite responder às adversidades da vida por meio de uma ativação contínua e de uma grande capacidade performativa. Trata-se de ordenar as coisas para permitir o livre desabrochar destas capacidades.

Os empreendedores seriam movidos por uma mistura entre senso de oportunidade e necessidade de sobrevivência. O peso distinto de cada um desses fatores depende, provavelmente, de onde os indivíduos estão colocados na escala social.

Hernando de Soto, consultor de organismos internacionais e do ditador peruano Fujimori, apresenta a favela do Terceiro Mundo como uma "economia povoada por empreendedores heroicos" (SOTO, 2001). A economia da favela é interpretada como um levante popular contra a burocracia estatal, uma revolução vinda de baixo. Para ele, essas economias são ricas em ativos, ainda que sob a forma defeituosa do capital morto. O "mistério do capital" é a forma como estes ativos e inativos defeituosos podem ser transformados em capital líquido, desencadeando, assim, novas fronteiras de acumulação de capital. São essas as receitas que hoje estão sendo seguidas pelos programas de formalização dos empreendimentos. $\mathrm{O}$ antigo trabalhador informal vira o contemporâneo empreendedor.

No livro que o Sebrae utiliza atualmente em seus cursos de formação sobre empreendedorismo (SEBRAE, 2002) encontramos a informação de que para cada oito brasileiros em idade adulta, um está abrindo ou pensando em abrir o seu negócio. O Brasil, aprendemos, é o país com a maior porcentagem de empreendedores da América Latina (SEBRAE, 2002, p. 13). Mas, por outro lado, de cada 100 empresas abertas, 35 não chegam ao final do primeiro ano, 46 do segundo e 56 do terceiro. Por que, então, órgãos públicos e privados, no país, estão apostando no empreendedorismo, apesar de ser um investimento tão incerto? No meu entender, o que está em jogo não é diretamente o retorno financeiro ou a saída da crise do capital, e sim a difusão de uma "subjetividade empreendedora". De acordo com Rose:

o vocabulário do empreendedorismo une a retórica política e os programas regulatórios às capacidades de "autodireção" das pessoas. [...] Refere-se a uma série de regras para a conduta da existência diária de uma pessoa: energia, iniciativa, ambição, cálculo e responsabilidade pessoal. O self empreendedor fará da sua vida um empreendimento, procurando maximizar seu próprio capital humano, projetando seu futuro e buscando se moldar a fim de se tornar aquilo que deseja ser. [...] O empreendedorismo designa uma forma de governo que é intrinsecamente "ética": o bom governo deve ser baseado nas maneiras pelas quais as pessoas governam a si próprias. (ROSE, 2011, p. 215).

Os indivíduos contemporâneos são incitados a viver como se fossem projetos, a se tornar, cada um, empresário de si mesmo. No âmbito da racionalidade neoliberal, 
a autonomia do self é, ao mesmo tempo, objetivo e instrumento das estratégias de governo.

A suposta autonomia dos trabalhadores "por conta própria" faz com que, além de assumir os riscos, eles tenham que assumir o ônus do fracasso em termos de responsabilização individual: se o negócio não deu certo, é porque ele não foi um "bom empreendedor", não tinha as qualidades e a ousadia necessárias. O peso subjetivo do fracasso é significativo, em particular para os jovens.

"Quando se pensa em trabalho, se pensa em geração de oportunidades", me disse um membro do Conselho Nacional de Juventude (Conjuve) durante uma entrevista. Essa frase sintetiza, a meu ver, uma "virada dos tempos". A ideia central é que cada indivíduo tem a responsabilidade de se aproveitar das oportunidades que aparecem no caminho. Aos agentes externos, especificamente ao Estado, cabe simplesmente oferecer (de forma difusa) essas oportunidades. Assim, o direito ao trabalho é transformado em geração de oportunidade. Portanto, hoje não se trata de facilitar o acesso dos jovens ao primeiro emprego, e sim de oferecer oportunidades. O termo oportunidade é sinônimo de ocasião, possibilidade. Toda uma série de traços de personalidade têm que ser coformada para aprimorar a capacidade dos indivíduos de aproveitar as oportunidades com agilidade.

Acredito que as atuais transformações no mundo do trabalho devem ser compreendidas sem cair na tentação de ficar presos a representações binárias. É preciso escapar tanto dos entusiasmos simplistas sobre a presumida potência transformadora quanto do cinismo resignado que só vê cooptação, captura e derrota pelo neoliberalismo, o capital e o mercado.

\section{Referências}

ALBERTI, V. Manual de História Oral. Rio de Janeiro: Ed. FGV, 2005.

ARANTES, O. Uma estratégia fatal: a cultura nas novas gestões urbanas. In: ARANTES O.; VAINER, C.; MARICATO, E. (Orgs.). A cidade do pensamento único: desmanchando consensos. Petrópolis: Vozes, 2000.

BOLTANSKI, L.; CHIAPELLO, E. O novo espírito do capitalismo. São Paulo: Martins Fontes, 2009.

BRANT, L. Políticas culturais. Barueri: Manole, 2003.

DELGADO, M. La artistización de las políticas urbanas: el lugar de la cultura en las dinamicas de reapropriación capitalista de la ciudad. Scripta Nova: Revista Eletrónica de Geografía y Ciencias Sociales, n. 12, p. 270, 2008. 
EHRENBERG, A. O culto da performance: da aventura empreendedora à depressão nervosa. Aparecida: Idéias e Letras, 2010.

EWALD, F. L'Etat Providence. Paris: B. Gasset, 1986.

GEM - GLOBAL ENTREPRENEURSHIP MONITOR. Empreendedorismo no Brasil: relatório executivo. Curitiba: Sebrae, 2013.

GILROY, P. Entre campos: nações, culturas e fascínio da raça. São Paulo: Annablume, 2007.

IBGE - INSTITUTO BRASILEIRO DE GEOGRAFIA E ESTATÍSTICA. Estatística de empreendedorismo: 2011. Rio de Janeiro: IBGE, 2012. (Estudos e Pesquisa, n. 22). NERI, M. A nova classe média. São Paulo: Saraiva, 2011.

POCHMANN, M. Nova classe média? O trabalho na base da pirâmide social brasileira. São Paulo: Boitempo, 2012.

RIO DE JANEIRO. Secretaria Municipal de Cultura do Rio De Janeiro. Prêmio de Ações Locais - Edição Rio 450. Rio de Janeiro: Secretaria Municipal de Cultura do Rio de Janeiro, 2014. (Edital de Seleção, n. 4).

ROSE, N. Inventando nossos selfs: psicologia, poder e subjetividade. Petrópolis: Vozes, 2011.

SEBRAE - SERVIÇO BRASILEIRO DE APOIO ÀS MICRO E PEQUENAS EMPRESAS. Aprender a empreender. Brasília: Sebrae; Fundação Roberto Marinho, 2002.

. Economia criativa do Rio de Janeiro e as MPE. Brasília: Sebrae, 2012.

SILVA, L. A. M. Da informalidade à empregabilidade (reorganização a dominação no mundo do trabalho). Cadernos CRH, Salvador, v. 15, n. 37, p. 81-109, 2002.

SINGER, A. Os sentidos do lulismo: reforma gradual e pacto conservador. São Paulo: Cia das Letras, 2012.

SOTO, H. O misterio do capital. Rio de Janeiro: Record, 2001.

SOUZA, J. Os batalhadores brasileiros: nova classe média ou nova classe trabalhadora? Belo Horizonte: Ed. UFMG, 2010.

TOMMASI, L. Nem bandidos nem trabalhadores baratos: trajetórias de jovens da periferia de Natal. Dilemas: Revista de Estudos de Conflito e Controle Social, v. 5, n. 1, p. 101-129, 2012.

. Tubarões e peixinhos: histórias de jovens protagonistas. Revista Educação e Pesquisa, São Paulo, v. 40, n. 2, p. 533-548, 2014. 
Jovens militantes: engajamento, implicação e desencanto. In: SILVA, G.; CORSINI, L. (Orgs.). Democracia x regimes de pacificação. São Paulo: Annablume, 2015.

TOMMASI, L.; NOGUEIRA, M.; CORROCHANO, M. C. Almanaque da Juventude e o Mundo do Trabalho. Recife: FES, 2007.

VELAZCO, D. O discurso da "cidade integrada" no Rio de Janeiro e suas implicações no cotidiano de jovens moradores da Cidade de Deus. 2014. Monografia (Graduação em Ciências Sociais) - Universidade Federal Fluminense, Niterói, 2014.

YÚDICE, G. A conveniência da cultura: uso da cultura na era global. Belo Horizonte: Ed. UFMG, 2006.

Recebido em julho de 2015.

Aprovado em novembro de 2015

Maria Livia de Tommasi é doutora em Sociologia pela Université de Paris I e professora do Departamento de Sociologia do Programa de Pós-Graduação Interdisciplinar Cultura e Territorialidades da Universidade Federal Fluminense (UFF). Coordena o Núcleo de Pesquisa Trabalho e Cultura na Cidade (Nutecc) do Conselho Nacional de Desenvolvimento Científico e Tecnológico (CNPa) e da UFF. Atua na área de Sociologia, com ênfase em Sociologia Urbana e Sociologia da Juventude. E-mail: <livia.detommasi@gmail.com>. 